\title{
A prática docente no contexto da sala de aula frente às reformas curriculares
}

\section{Classroom teaching practice facing curriculum reform}

\author{
Giseli Barreto da Cruz
}

\begin{abstract}
RESUMO
No presente texto, busco refletir acerca da importante posição a ser assumida pelos professores nos processos que desencadeiam reformas curriculares. Tendo em vista que a implementação de propostas voltadas para o contexto da sala de aula depende diretamente do papel exercido pelo professor, chamo atenção para a necessidade do seu protagonismo desde a fase da concepção. Para tanto, organizo a argumentação em dois grandes pontos: no primeiro, discuto o lugar historicamente ocupado pelo docente no decorrer das reformas, recorrendo à perspectiva defendida e experimentada pelo inglês Lawrence Stenhouse, baseada na crença na capacidade de os professores se desenvolverem profissionalmente com base na pesquisa, desenvolvendo currículo. No segundo ponto, procuro evidenciar que a prática docente se constitui em um exercício que transcende a dimensão técnica, não podendo ser assumida tão-somente como o atendimento às prescrições curriculares desenvolvidas por outros. Recorro, nesse ponto, ao pensamento de autores como Gauthier e Mellouki, Giroux, Vorraber Costa e Moreira para demarcar o caráter de mediação que marca a prática docente em sala de aula.

Palavras-chave: prática docente; reforma curricular; papel do professor.
\end{abstract}

\begin{abstract}
This text seeks to reflect on the central role teachers should play in processes leading to curriculum reform. Bearing in mind that the implementation of proposals focussing on the classroom context is directly dependent on the role played by the teacher, we would like to stress the need for this player

* Doutora em Educação pela PUC-Rio.
\end{abstract}


to take on a leading role from the start of any such project. To this end, the text puts forward two major arguments: the first one discusses the place historically occupied by teachers in school reforms, taking as a starting point Lawrence Stenhouse's views on teachers' professional development based on research Carried out in the context of curriculum development. The second argument put forward the point that teaching practice transcends the technical dimension, often going beyond limits set by external curricular prescriptions. This point is supported by arguments developed by a number of authors such as Gauthier and Mellouki, Giroux, Vorraber Costa e Moreira whose vision of the teachers' role is that of mediators between different players and pressures affecting classroom practice.

Key-words: teaching practice; curriculum reform; teacher's role.

\section{Introdução}

Falar de prática docente em sala de aula é falar de um saber-fazer do professor repleto de nuances e de significados. Implica falar que os professores possuem saberes profissionais cheios de pluralidade (TARDIF, 2000) que vêm à tona no âmbito de suas tarefas cotidianas. Não só saberes, mas, também, sensibilidades cultivadas ao longo de sua formação e atuação que orientam sua ação no contexto de uma sala de aula. Falar de prática docente exige, portanto, que falemos de sujeitos que possuem um ofício (ARROYO, 2000), o saber de uma arte, a arte de ensinar, e que produzem e utilizam saberes próprios de seu ofício no seu trabalho cotidiano nas escolas.

Nesse sentido, os professores ocupam uma posição central em relação às propostas curriculares. São eles os principais atores - sujeitos sociais que exercem a função de mediação da cultura e dos saberes escolares. Por que, então, as reformas curriculares insistem em desconsiderar ou agregar um valor secundário ao papel do professor, mesmo reconhecendo ser ele um sujeito fundamental para o processo de sua implementação? Apesar do campo educacional registrar uma multiplicidade de estudos sobre subjetividade, identidade, carreira, processos de formação e constituição de saberes docentes, as políticas educacionais tentam, mas não conseguem efetivamente, favorecer que os que atuam na escola participem do processo reformativo, subsidiando a formulação de propostas curriculares. 
É sobre o papel do professor, no contexto da sala de aula, como mediador do saber escolar, na perspectiva do currículo, que desejo fazer uma reflexão neste trabalho.

\section{Qual é o lugar devido à prática docente nos processos de reformas curriculares?}

De um modo geral, os teóricos das questões do currículo estão atentos à importância do papel do professor no processo de implementação das reformas, chamando, sempre que possível, atenção para esse fato. Entretanto, a atuação do professor ainda se dá em uma perspectiva secundária.

Le Shulman (1997), falando em um encontro de professores, enfatiza a necessidade das reformas educacionais considerarem os professores como aliados. O autor sinaliza, pelo menos, cinco aspectos em torno dessa questão: primeiro, os professores enfrentam um enorme desafio quando tentam ser profissionais responsáveis em meio ao turbilhão de encaminhamentos comuns ao período de implantação de uma reforma; segundo, o magistério se constitui em uma profissão de alto nível de exigência intelectual, técnica e emocional; terceiro, para que qualquer reforma funcione não só os alunos devem aprender, mas também os professores e, para tanto, ao menos seis princípios devem ser considerados (atividade, reflexão, colaboração, tempo, paixão e cultura); quarto, formação prévia e formação em serviço precisam ser igualmente cuidadas na formação docente; e quinto, as reformas, tal como vêm sendo encaminhadas, dificultam a atuação do professor e, conseqüentemente, afetam o seu êxito.

No decorrer da sua argumentação, Shulman defende que qualquer reforma deve respeitar o saber dos profissionais. O que necessariamente não acontece. Pelo contrário, segundo o autor, as reformas são marcadas pela separação entre concepção e fazer e organização rígida, elaborada à distância e desconectada da prática cotidiana da sala de aula.

Candau (1999), discorrendo sobre as reformas educacionais da atualidade na América Latina, chama atenção para as "palavras de ordem" que marcam as propostas que se tentam pôr em prática nos diferentes contextos: (...) descentralização, qualidade, competitividade, eqüidade, reforma curricular, transversalidade, novas tecnologias, dentre outras de caráter 
mais secundário. (p. 29) Observa-se que, de um modo geral, elas apontam para o ofício do professor. Mas, ainda assim, o mestre desse ofício não galga uma posição mais privilegiada na condução da mudança. Pelo contrário, como sinaliza Candau (p. 31), há uma distância significativa entre as propostas oficiais e o dia-a-dia das escolas e os dilemas que os professores enfrentam no encaminhamento de seu trabalho.

A intenção de Candau, nesse texto, é a de questionar o sentido do discurso presente nas reformas, a maneira como ele vem sendo construído, quem são os seus principais atores e quais os seus eixos estruturantes. Entretanto, a autora, no decorrer de sua argumentação, acaba levantando suspeita sobre a unanimidade em torno desse discurso, assentado nas propostas do Banco Mundial, e defendendo uma outra reforma, seguindo na direção apontada pela educadora argentina Adriana Puigrós (1997). Uma outra reforma, cujo apoio estaria firmado nas pessoas e o eixo central nas questões relativas à identidade, às condições de trabalho e à profissionalização dos professores. Isto significa colocar os professores no seu lugar de direito, isto é, o de principais protagonistas desse processo.

Olhando para o contexto da prática pedagógica, para onde as reformas se dirigem, e falando como alguém que atua nesse contexto, é possível afirmar que existem estratégias variadas por parte dos curriculistas, dos representantes dos órgãos centrais e dos governantes, representantes e proponentes de políticas públicas, no sentido de envolver os docentes no processo de concepção, implantação e implementação das propostas. Todavia, o esforço é ínfimo diante do alcance que se espera com os "novos" redimensionamentos curriculares. O movimento das reformas, via de regra, é marcado de cima para baixo, quando o contrário representaria a lógica mais viável. Pois é no seio da sala de aula que o conhecimento curricular, alvo das propostas, vai se desenvolver de forma mais direta e sistemática e são os professores, mestres do ofício de ensinar, os sujeitos sociais mais importantes no encaminhamento desse processo. O movimento que emana do microcontexto da sala de aula pode representar, então, um caminho mais viável para a consolidação de mudanças educacionais.

Esta idéia nos remete ao pensamento de Lawrence Stenhouse (1975), um estudioso das questões de currículo e que se tornou uma referência, tanto no que tange ao papel do professor frente às reformas curriculares quanto à idéia de professor pesquisador. Suas reflexões se situam nas décadas de 60 e 70 na Inglaterra e se baseiam na crença na capacidade de os professores se desenvolverem profissionalmente com base na pesquisa, desenvolvendo currículo. 
Para Stenhouse, a pesquisa deveria ser a base do ensino dos professores, tendo como foco central o currículo, uma vez que é por seu intermédio que se transmite o conhecimento na escola. De acordo com o que propunha Stenhouse (1975), as reformas precisariam incluir em seu interior o desenvolvimento profissional dos professores como pesquisadores de suas próprias práticas, que fazem de suas salas de aula típicos laboratórios de ensino.

Em 1966, quando o sistema educacional inglês vivia as expectativas de implementação de uma reforma curricular, Stenhouse, trabalhando no Schools Council for Curriculum and Examinations (Conselho Escolar de Currículo e Avaliação), assumiu a direção do Humanities Project, voltado especificamente para jovens estudantes das escolas secundárias. A onda de reforma educacional da Inglaterra, na década de 60 , atenta às escolas que ofereciam um currículo menos denso, cujos alunos, em geral, não eram preparados para níveis mais avançados, instituiu tal Conselho com a finalidade de respaldar a reforma nas áreas do currículo e de avaliação. A implantação do Conselho de Escola representava a necessidade de investir em uma concepção diferenciada da natureza do conhecimento escolar e, conseqüentemente, como o conhecimento deveria ser trabalhado junto aos professores e aos estudantes. Stenhouse, na condição de representante de um órgão central, vai trabalhar no contexto da sala de aula, junto aos seus professores, com o projeto de humanidades, assumindo como pressupostos de sua ação os princípios que informam a relação entre ensino e pesquisa, e tendo como objeto de trabalho curricular as questões humanitárias de caráter controvertido que atravessavam diretamente a vida cotidiana dos estudantes dessas escolas ${ }^{1}$.

Trata-se de uma experiência que leva em conta o fato de que os professores produzem em suas práticas uma riqueza de conhecimentos que precisa ser, juntamente com as suas vivências, assumida como ponto de partida de qualquer processo de aperfeiçoamento de seu trabalho e de mudança curricular.

Stenhouse acreditando na capacidade dos professores, potencializada pela mútua colaboração entre eles e os pesquisadores acadêmicos de elaborar um currículo em contínuo desenvolvimento e reavaliação, que contri-

1 Para aprofundamento da temática, ver: ELLIOTT, J. The teachers' role in curriculum development: an unresolved issue in english attempts at curriculum reform. In: The curriculum experiment: meeting the challenge of social change. Buckingham: Open University Press, $\mathrm{p}$ 17-41, 1998. 
buísse para a emancipação dos sujeitos que convivem na escola, vai para além do Humanities Project, vinculado à Schools Council for Curriculum and Examinations, e funda o C.A.R.E. (Center for Applied Research in Education - Centro de Pesquisa Aplicada à Educação), na Universidade de East Anglia, na Inglaterra, na década de 70, trabalhando para que a pesquisa fosse a base do ensino dos professores de todos os níveis, e não só da Universidade.

J. Elliott (1998), que foi discípulo de Stenhouse, fez parte da sua equipe, ajudando a desenvolver o projeto curricular experimental sobre questões humanitárias diversas e controvertidas e foi um dos diretores do C.A.R.E., considera que o modelo de desenvolvimento curricular de Stenhouse supõe uma compreensão de conhecimento profissional e de suas relações com a prática educativa completamente distinto do modelo da racionalidade técnica, já que o atrela aos docentes mais do que aos pesquisadores especializados.

Elliott (1998) destaca que para Stenhouse os professores são talvez as pessoas mais capazes de elaborar um currículo que contribua, de fato, para a emancipação dos alunos enquanto sujeitos sociais. Pois ele parte de uma concepção de currículo entendido como um conjunto de procedimentos hipotéticos, do qual poderiam se valer os professores para transformar idéias educativas em ações educativas. Nessa direção, o currículo se configura em um processo que exige do professor conhecimentos, sensibilidade, capacidade de reflexão e dedicação profissional, já que tem em vista o encaminhamento do ensino/aprendizagem adequado ao ritmo e às peculiaridades do aluno.

Elliott enfatiza, ainda, que, segundo Stenhouse, não há desenvolvimento curricular sem desenvolvimento de professores. O currículo é meio de desenvolvimento profissional na medida em que pode ser recriado pelos professores mediante o confronto com as questões comuns à sala de aula.

Dessa forma, tanto Stenhouse quanto Elliott se opunham frontalmente à idéia de currículo como listagem de conteúdos a serem desenvolvidos pelo professor com seus alunos através de um plano racional em que conteúdos e métodos eram concebidos como instrumentos para inculcar nos alunos conhecimentos previamente elaborados.

É importante dizer que, em função de suas idéias e investidas práticas, Stenhouse se situa na contracorrente dos estudos em Educação predominantes nas décadas de 60 e 70 , fortemente marcados por uma concepção de currículo vinculado à orientação tecnicista. A teoria educacional se configurava em um campo cada vez mais acadêmico e de convergência 
de uma multiplicidade de orientações teóricas, assumindo para si a responsabilidade de apontar princípios orientadores para a prática, reduzindo esta a uma atividade meramente técnica. $O$ caráter técnico da educação reforça a clássica separação entre quem planeja a educação e quem a faz. Portanto, aos professores caberia a aplicação de currículos pensados por outros, assumindo um papel que, no dizer de Elliott (1998), continua representando uma questão não resolvida nas diferentes ondas de reformas curriculares.

\section{Prática docente, um exercício para além da técnica}

A escola possui uma missão cultural, tornando-se elemento-chave para a articulação de interesses, de gostos e de socialização de aspectos históricos, sociais e culturais, sendo os professores os seus catalizadores, acelerando ou retardando o processo. A atuação do professor é estratégica, exercendo um papel de tradutor da idéia oficial para o contexto da prática.

Nessa perspectiva, a prática docente no contexto da sala de aula não pode ser encarada como um exercício meramente técnico, marcado pelo atendimento às prescrições curriculares desenvolvidas por outrem. Os aspectos que perpassam o ofício do professor são múltiplos e complexos, inviabilizando qualquer tentativa de redução da sua ação.

O ofício do professor implica no manejo de técnicas, mas não só isso. Trata-se de um misto de habilidades que não podem ser engessadas nesse quesito. Diversas questões instigam o trabalho cotidiano do professor exigindo reflexão, análise de situações e tomada de posição. As técnicas, sejam elas de que tipo for, serão sempre meios para o professor articular conhecimentos gerais e disciplinares com vistas à aprendizagem de seus alunos. Falamos, portanto, de um trabalho de mediação em que o professor, mais do que um técnico, representa um tradutor e um difusor do conhecimento. Nesse processo de mediação, se revelam as nuances de seu ofício em que ele, a partir das análises dos fundamentos sociais e culturais do currículo, encaminha a sua ação no contexto da sala de aula, fazendo a interpretação e a crítica, produzindo e organizando conhecimentos, identificando e escolhendo técnicas e métodos pedagógicos para a socialização das experiências de aprendizagem de seu grupo de ensino. 
No plano da formação e do exercício profissional, o que caracteriza o professor não é exclusivamente o domínio de uma disciplina, mas o de um conjunto de conhecimentos, que chamamos de saber docente (TARDIF, 2000), que inclui uma gama não só de saberes, mas também de práticas relativas ao ofício de ensinar. Nessa direção, o ofício do professor implica um saber fazer que assegure a aprendizagem da disciplina e a transmissão do que lhe é confiado pela via das diretrizes curriculares e que, inevitavelmente, expressa uma determinada concepção de mundo.

Nesse sentido, o professor tem uma importante função social a exercer. Gauthier e Mellouki (no prelo), em artigo ainda não publicado ${ }^{2}$, desenvolvem uma interessante abordagem do professor como mediador, herdeiro, crítico e intérprete da cultura, exercendo o papel de intelectual na escola e na sociedade. Argumentam que pelo menos três razões sustentam a inserção do professor na categoria de intelectuais: o trabalho de quem ensina é de natureza intelectual, não podendo ser reduzido às suas dimensões instrumentais e técnicas; existem condições ideológicas e práticas indispensáveis ao exercício do ensino como trabalho intelectual; e o professor contribui, através das abordagens pedagógicas que adota e utiliza, com a produção e legitimação de interesses políticos, econômicos e sociais de certos grupos sociais em detrimento de outros.

Giroux (1997), em conhecido ensaio, já trabalhava com a tese do professor como intelectual em contraposição à de professor como técnico. Nesse texto em especial ${ }^{3}$, aponta que as reformas educacionais dos anos 90 representam para os professores, de um lado, uma ameaça e, de outro, um desafio. Três motivos traduzem o clima de ameaça das reformas: primeiro, elas demonstram pouca confiança na capacidade dos professores de se constituírem como líderes intelectuais; segundo, elas ignoram o papel dos professores no que tange à formação para a cidadania; e terceiro, elas reduzem a atuação dos professores ao status de técnico.

Diante do caráter ameaçador das reformas curriculares, Giroux destaca que a melhor postura dos professores reside em assumi-las como um desafio. $\mathrm{O}$ desafio de encarar um processo de autocrítica em relação à natureza e finalidade da sua formação e atuação para, então, unir-se ao

2 Artigo estrangeiro intitulado "L'enseignant et son mandat: Médiateur, héritier, interprète, critique" aprovado para publicação na Revista Científica Educação e Sociedade n. 87.

GIROUX, Henry. Professores como intelectuais transformadores. In: Os professores como intelectuais: rumo a uma pedagogia crítica da aprendizagem. Porto Alegre: Artes Médicas, p.157-164, 1997. 
debate público com os críticos, enfatizando a posição estratégica que ocupam e organizar-se coletivamente para, dentre outras coisas, lutar por melhores condições de trabalho. Nessa direção, a postura de dispor-se ao debate representa o eixo central da luta dos professores, o que implica no desenvolvimento de uma perspectiva teórica que redefina a natureza da crise educacional e forneça as bases para uma visão alternativa à formação e atuação docentes.

A ameaça de desvalorização e desabilitação do trabalho docente precisa ser vencida pela assunção do desafio dos professores se assumirem e serem assumidos como intelectuais transformadores. Conceber o trabalho dos professores como intelectual implica reconhecer e questionar sua natureza socialmente construída e o modo como se relaciona com a ordem social, assim como analisar as possibilidades transformadoras implícitas no contexto social das aulas e do ensino. O intelectual crítico é aquele que participa ativamente do esforço de desvelar o oculto e desvendar a origem histórica e social daquilo que se apresenta como natural.

Para Giroux, a categoria de intelectual é particularmente representativa no processo de luta contra o desenvolvimento crescente de ideologias instrumentais que enfatizam uma abordagem tecnocrática para a formação e atuação docentes porque possibilita, ao menos, três contribuições: a oferta de uma base teórica capaz de romper com a marca de que o exercício docente é algo meramente técnico; o esclarecimento dos tipos e condições ideológicas e práticas necessárias para que os professores atuem como típicos intelectuais; e a definição do papel que os professores desempenham na produção e legitimação de interesses políticos, econômicos e sociais.

A consideração do professor não só como intelectual, mas como intelectual transformador, cuja tônica está em tornar o pedagógico mais politico e o político mais pedagógico (GIROUX, 1997, p. 163), favorece a reflexão sobre os princípios que estruturam a vida prática em sala de aula, bem como a análise crítica das condições que organizam as práticas ideológicas e materiais de ensino, firmando o professor na posição central que ocupa, junto ao aluno, no processo de aprendizagem, alvo das reformas.

Tal aspecto reforça a crença que desenvolvemos de que, no contexto da sala de aula, o professor possui uma missão que não se desenvolve apenas através de um exercício técnico. A missão do professor implica, entre outras coisas, na divulgação da cultura junto às gerações mais jovens, na perspectiva de que é aquele que detém um poder simbólico e institucional para condução das formas culturais de pensar e agir em sociedade. Dessa forma, dependendo do modo como o professor lida com o seu papel, o seu 
trabalho pode representar uma ameaça ou não à conservação do status quo. Um exercício para além da técnica.

O caráter político-cultural que atravessa o trabalho pedagógico nos remete à discussão encaminhada por Vorraber Costa (1998) acerca da relação entre currículo e política cultural. No decorrer do texto, a autora, inspirada nas perspectivas pós-estruturalistas e pós-modernas no que tange às relações entre cultura, conhecimento, saber e poder e ancorada nas discussões geradas pelos estudos culturais, busca examinar o currículo escolar como um terreno privilegiado de política cultural e perpassado por múltiplos elementos que estão implicados em relações de poder. Nessa direção, procura analisar a escola e seu currículo como um espaço marcado pela produção, circulação e consolidação de significados.

Dentre as concepções exploradas por Vorraber Costa, a de currículo é particularmente representativa no contexto da argumentação que buscamos construir neste trabalho. Para a autora,

o currículo e seus componentes constituem um conjunto articulado e normatizado de saberes, regidos por uma determinada ordem, estabelecida em uma arena em que estão em luta visões de mundo e onde se produzem, elegem e transmitem representações, narrativas, significados sobre as coisas e seres do mundo.” (VORRABER COSTA, 1998, p. 41)

Embora a intenção da autora seja a de tomar a noção de poder como central nessa concepção, para evidenciar que quem tem força determina as representações sociais de sua cultura particular, nos limitamos aqui apenas a demarcar a atuação do professor como algo determinante para a consolidação da prática curricular no contexto da sala de aula. O professor, como um dos atores/sujeitos sociais do processo educativo, detém uma visão de mundo, sociedade, educação e homem que influenciará diretamente no tipo de encaminhamento que imporá à sua prática pedagógica.

Em função disso é que temos reafirmado, no decorrer deste trabalho, a idéia de que o professor ocupa uma posição estratégica. A sala de aula, lugar de sua atuação, se situa entre as diretrizes da escola e as do sistema de ensino. Dificilmente as propostas dispensam a ação docente, uma vez que o professor exerce o papel central de tradutor da idéia oficial para o contexto da prática. 
Todavia, historicamente, as reformas curriculares vêm enfrentando um fosso entre implantação e implementação. As políticas educacionais propõem a implantação de novas estratégias de organização do conhecimento escolar, que não chegam a serem implementadas efetivamente no contexto da sala de aula porque, via de regra, tendem a considerar a ação docente numa perspectiva bastante restritiva.

Amaral (2003), em recente texto intitulado "Conflito conteúdo/forma em pedagogias inovadoras: a pedagogia de projetos na implantação da escola plural", procura discutir a dificuldade enfrentada por professores no processo de implementação de propostas pedagógicas inovadoras no que se refere à relação forma/conteúdo. Parte do pressuposto de que é falsa a dicotomia entre conteúdo e forma. Mas reconhece que existe uma tensão no meio dos professores no que se refere à necessidade de conciliar metodologias ativas com conteúdos formais e necessários à formação do aluno. O texto decorre de uma pesquisa realizada pelo GAME - Grupo de Avaliação e Medidas educacionais da UFMG - em escolas municipais de Belo Horizonte, MG, no decorrer do ano de 1999, voltada para o movimento da escola plural.

A autora, após discutir os pressupostos que perpassam a idéia de interdisciplinaridade, bem como os princípios e as características dos projetos de trabalho, concepções nucleares da proposta da escola plural, elabora uma análise sobre como os professores que atuam na escola plural vêm lidando com os projetos de trabalho. Nessa direção, sinaliza que a concepção de conhecimento subjacente à pedagogia de projeto ainda não foi suficientemente internalizada pelos professores, os sujeitos que lidam diretamente com a organização do conhecimento escolar, o que gera no imaginário do corpo docente, de um modo geral, a representação de que ao se trabalhar com projetos rompe-se com o conteúdo formal. Tal representação obstaculiza a implementação da proposta. Pois, para os professores, repensar os conteúdos adquire contornos de abandoná-los, criando uma falsa dicotomia entre projeto de trabalho e conteúdo, a ponto de se forjar a crença de que a opção por conteúdos representaria uma traição à idéia da escola plural.

A situação da rede municipal de Belo Horizonte não é muito diferente das demais redes de ensino diante das suas políticas de reformas educacionais. $\mathrm{O}$ estranhamento experimentado pelos professores deve-se em grande parte pelo seu distanciamento do processo de concepção da proposta e pela ausência de um programa de formação continuada articulado às reais necessidades da prática pedagógica. 
Os professores precisam participar mais do processo de reformulação curricular. É importante e necessário que eles assumam uma das posições de sujeitos construtores das diretrizes curriculares, como condição para o favorecimento de um trajeto menos conflituoso entre o que se propõe e o que se faz.

Moreira (1998), ao discutir a crise da teoria curricular crítica, procura evidenciar que a desestrutura da sociedade atual como um todo repercute no campo da educação, estremecendo as bases dos estudos curriculares. O currículo, ao se voltar para as relações entre o conhecimento escolar e a estrutura de poder na sociedade mais ampla, sofre de forma aguda as incertezas que marcam o campo.

Todavia, Moreira busca examinar as contradições e os impasses que perpassam o pensamento curricular visando indicar novas possibilidades diante das crises. Para tanto, retoma a trajetória da teoria curricular crítica no Brasil, evocando os principais estudos a seu respeito, e sinaliza que um dos aspectos críticos da Teoria Curricular Crítica, que vem se insinuando na produção acadêmica, está no distanciamento entre o que se formaliza teoricamente e o que, de fato, acontece no contexto cotidiano das escolas, reforçando o fosso entre o currículo formal e o currículo em uso. Reside nesse movimento o ponto que nos interessa: a teoria não se transforma em ação porque conta com propostas que não são satisfatoriamente compreendidas pelos professores.

A prática cada vez mais vem alcançando posição central, tanto na rediscussão do currículo, como da Educação de um modo geral. É preciso assumir a centralidade da prática, considerando professores e alunos, aqueles que nela atuam, como sujeitos nucleares do processo de teorização do currículo.

Nessa direção, Moreira sugere aos curriculistas que atuem nas diferentes instâncias da prática curricular e desenvolvam investigações da prática com os que nela atuam para subsidiar a formulação de políticas de currículo, favorecer a renovação pedagógica e promover o avanço da teoria. Trata-se, portanto, de considerar o lugar central do professor diante da prática curricular a partir de uma concepção de trabalho docente que implica em um saber fazer para além da técnica. 


\section{Para finalizar}

Ter clareza acerca do papel cultural da escola é algo importante e necessário. No entanto, é preciso, além disso, definir a maneira como esse papel é apontado nos programas escolares e nas práticas dos professores. Mais do que definir o conteúdo cultural que integrará os programas curriculares, é preciso sinalizar as orientações ou os princípios que guiarão as escolhas culturais dos professores. Como serão desenvolvidas as práticas culturais e como será encaminhado o processo de avaliação? Quais são as abordagens pedagógicas apropriadas para favorecer o desenvolvimento cultural no meio escolar? Quais os espaços e tempos apropriados para práticas dessa natureza? Questões desse tipo precisam integrar os programas de reformas curriculares. Estas, por sua vez, não podem ser encaminhadas por um grupo seleto e distante do contexto onde a prática pedagógica se desenvolve. Os professores, como intérpretes e críticos da cultura, possuem conhecimentos que lhes permitem participar de um processo de definição do papel e da perspectiva cultural do ensino que ministram.

Diferentemente disso, a onda de reformas nos últimos anos não tem deixado muito tempo para que os professores assimilem as modificações introduzidas pelas propostas oficiais. As mudanças encaminhadas, justamente por não contarem com a participação direta dos professores no seu processo de elaboração, encontram neles próprios típicos obstáculos à sua implementação. Se, por um lado, existem alterações na dinâmica curricular que agradam aos professores, por outro existem modificações que não são bem aceitas. Principalmente aquelas que interferem diretamente nas suas rotinas de trabalho.

Vivemos sob as expectativas de propostas que buscam alterar a estrutura escolar, tais como: ciclos em lugar de série; avaliação continuada em lugar de aprovação ou reprovação; classes de aceleração e/ou reorientação da aprendizagem buscando atacar a distorção série/idade e as dificuldades generalizadas de aprendizagem; o ensino por competências; o ensino com temas transversais; o trabalho com projetos educativos, e assim por diante. Nem todas as propostas são nocivas e buscam atravancar o trabalho pedagógico, cuja especificidade reside na aprendizagem do aluno. Pelo contrário, algumas delas apontam para direções bem interessantes. Todavia, o distanciamento entre a sua concepção e o envolvimento do professor acaba se constituindo em um elemento crucial para determinar seu sucesso ou fracasso. 
Como diz Arroyo (2000), é preciso repor os mestres no lugar de destaque que lhes cabe. O professor, que mais parece um cata-vento que gira à mercê da última vontade política e da última demanda tecnológica, precisa ser visto como sujeito central em qualquer processo de reformulação curricular. Isto porque a atuação do professor implica na articulação de uma gama de saberes construídos no cotidiano do seu exercício profissional, a partir dos quais ele interpreta, compreende e orienta qualquer investida curricular no contexto de sua sala de aula.

\section{REFERENNCIAS}

AMARAL, A. L. Conflito conteúdo/forma em pedagogias inovadoras: a pedagogia de projetos na implantação da escola plural. In: MARIN, A. J.; SILVA, A. M. M.; SOUZA, M. I. M. (Orgs.). Situações didáticas. Araraquara: JM Editora, p. 223-235, 2003

ARROYO, M. Oficio de mestre: imagens e auto-imagens. Petrópolis, RJ: Vozes, 2000.

CANDAU, V. M. Reformas educacionais hoje na América Latina. In: MOREIRA, A. F. (Org.) Currículo, políticas e práticas. Campinas, SP: Papirus, p. 29-42, 1999.

COSTA, M. V. Currículo e política cultural. In: COSTA, M. V. (Org.). O currículo nos limiares do contemporâneo. Rio de Janeiro: DP\&A, p.37-67, 1998.

ELLIOTT, J. The teachers' role in curriculum development: an unresolved issue in english attempts at curriculum reform. In: The curriculum experiment: meeting the challenge of social change. Buckingham: Open University Press, p. 17-41, 1998.

GAUTHIER, C; MELLOUKI, M. L'enseignant et son mandat: médiateur, héritier, interprète, critique. Artigo estrangeiro aprovado para publicação na Revista Científica Educação e Sociedade, n. 87, 1998.

GIROUX, H. Professores como intelectuais transformadores. In: Os professores como intelectuais: rumo a uma pedagogia crítica da aprendizagem. Porto Alegre: Artes Médicas, 1997. p. 157-164.

MOREIRA, A. F. B. A crise da teoria curricular crítica. In: COSTA, M. V. (Org.). $O$ currículo nos limiares do contemporâneo. Rio de Janeiro: DP\&A, p. 11-36, 1998.

SHULMAN, L. Ensino, formação de professor e reforma escolar. In : CASTRO, C. de M.; CORNOY, M. (Orgs). Como anda a reforma da educação na América Latina? Rio de Janeiro: Fundação Getúlio Vargas, p. 133-139, 1997. 
STENHOUSE, L. An introduction to curriculum research and development. Londres: Heinemann, 1975.

TARDIF, M. Elementos para uma epistemologia da prática profissional dos professores e suas conseqüências em relação à formação do magistério. Universidade de Laval/ PUC-Rio, 2000. (mimeo.)

Texto recebido em 22 jun. 2006 Texto aprovado em 14 nov. 2006 